\title{
Efficient Analyte Oxidation in an Electrospray Ion Source Using a Porous Flow-Through Electrode Emitter
}

\author{
Gary J. Van Berkel, Vilmos Kertesz, and Michael J. Ford \\ Organic and Biological Spectrometry Group, Chemical Sciences Division, Oak Ridge National Laboratory, \\ Oak Ridge, Tennessee, USA
}

Michael C. Granger

ESA, Inc., Chelmsford, Massachusetts, USA

\begin{abstract}
This article describes the components, operation, and use of a porous flow-through electrode emitter in an electrospray ion source. This emitter electrode geometry provided enhanced mass transport to the electrode surface to exploit the inherent electrochemistry of the electrospray process for efficient analyte oxidation at flow rates up to $800 \mu \mathrm{L} / \mathrm{min}$. An upstream current loop in the electrospray source circuit, formed by a grounded contact to solution upstream of the emitter electrode, was utilized to increase the magnitude of the total current at the emitter electrode to overcome current limits to efficient oxidation. The resistance in this upstream current loop was altered to control the current and "dial-in" the extent of analyte oxidation, and thus, the abundance and nature of the oxidized analyte ions observed in the mass spectrum. The oxidation of reserpine to form a variety of products by multiple electron transfer reactions and oxidation of the ferroceneboronate derivative of pinacol to form the ES active radical cation were used to study and to illustrate the performance of this new emitter electrode design. Flow injection, continuous infusion, and on-line HPLC experiments were performed. (J Am Soc Mass Spectrom 2004, 15, 1755-1766) (C) 2004 American Society for Mass Spectrometry
\end{abstract}

$\mathrm{E}$ lectrospray mass spectrometry (ES-MS) is now a firmly established, analytically important and versatile analysis tool $[1,2]$. Nonetheless, research continues to obtain a more thorough understanding of the underlying physics and chemistry of the ES ion source to enhance and expand the capabilities of ES-MS. Much of our research has been focused on understanding the analytical impact of the controlled-current electrochemistry (CCE) inherent to the operation of this ion source [3, 4]. This electrochemical process enables the quasi-continuous production of charged liquid droplets from the source and ultimately gas-phase ions sampled into the mass spectrometer. Oxidation in positive ion mode and reduction in negative ion mode are the predominating reactions at the emitter electrode which supply the excess of one ion polarity in solution that causes droplet charging. Many studies have been aimed at means to either avoid the possible impact of this inherent electrochemistry in analytical measurements or to develop means to exploit the electrochemistry for analytical advantage. Most research

Published online October 28, 2004

Address reprint requests to Dr. G. J. Van Berkel, Organic and Biological Mass Spectrometry Group, Chemical Sciences Division, Oak Ridge National Laboratory, 1 Bethel Valley Rd., Bldg. 5510, Oak Ridge, TN 37831-6131, USA. E-mail: vanberkelgj@ornl.gov in these two different areas is discussed in the recent review by Diehl and Karst [5].

In this article, we further address the means to exploit the inherent electrochemistry of the ES ion source for analytical advantage through efficient analyte electrolysis at the emitter electrode. Efficient analyte electrolysis can be utilized, for example, to enhance analyte ionization and detection [6-9], to create in abundance and study ions not normally produced by an ES ion source or by other ionization sources (e.g., multiply-charged cations formed by electron loss) $[10,11]$ or to study the products of electrode reactions and their homogenous reaction products [12]. A major advantage of using the inherent CCE process for these applications is simplicity, versus, for example, a discrete controlled-potential electrochemical (CPE) cell added upstream in the system, or a controlled potential emitter cell [13-15]. Only the ES emitter electrode is needed and no additional control devices are required. Another advantage over an upstream cell is the proximity of the electrochemistry to the point of transfer of solution species into the gas-phase. This dramatically shortens the time for homogenous chemistry involving the electrochemically generated products.

One possible limitation of the CCE process of ES in 
analytical use is that the interfacial working electrode potential cannot be finely controlled as in the case of a CPE cell [16]. The interfacial potential is a complex function of the current density (determined by the magnitude of the current and the effective electrode area) and the flux of the various species in solution to the electrode, along with their various electrochemical properties. Thus, at the ES emitter electrode, the interfacial potential and the electrochemical reactions that occur can change even though the current and voltage drop between electrodes do not, if there is a change in concentration or identity of the reacting species. Nonetheless, operational conditions can be achieved where the interfacial potential can be expected to approach that of the equilibrium potential for the major species in the system, i.e., solvents and additives, and therefore exceed $1.0 \mathrm{~V}$ vs $\mathrm{Ag} / \mathrm{AgCl}$ in positive ion mode [7]. Approximate potentials of lower magnitude can be maintained by addition of appropriate redox buffers to the system $[17,18]$.

The two other more limiting concerns have been the magnitude of the current at the ES emitter electrode and the mass transport of the analyte to the electrode surface $[3,7,16]$. To maximize analyte electrolysis the magnitude of the current at the ES emitter electrode must be sufficient for complete electrolysis of the molar equivalent of the analyte flowing through the emitter electrode as calculated using Faraday's law. Addition of an ES friendly electrolyte to solution (e.g., lithium triflate in nonpolar solvents or ammonium acetate in aqueous solvents) has proven to be one means to substantially increase the magnitude of the ES current and enhance electrolysis efficiency without inhibiting gas-phase ion formation [7]. Efficient analyte electrolysis also requires that all the analyte be transported to the electrode surface on passage through/by the electrode. With regard to this mass transport issue, we have shown that physically long ( $\gg 1 \mathrm{~mm}$ long), noncorrosive (e.g., platinum) tubular electrodes operating with solvent flow rates of less than about $5 \mu \mathrm{L} /$ min generally enhance analyte oxidation efficiency (via direct heterogeneous electron transfer). These conditions maximize the time available (electrolysis time) for analyte transport to the electrode via convective-diffusive flux [16]. More recently, we demonstrated that a planar, thinchannel electrode emitter geometry further improved analyte oxidation efficiency due to enhanced mass transport to the emitter electrode [19].

In any case, the general utility of the electrolysis process inherent to ES for analyte electrolysis is still limited by the inability to obtain high analyte electrolysis efficiency at solution flow rates greater than a few tens of microliters per minute $[16,19]$. In this study, we show that this limitation for analyte oxidation can be overcome by the use of a porous flow-through (PFT) electrode emitter. This electrode geometry provides for efficient mass transport of the analytes to the electrode surface even at flow rates of several hundred microliters per minute. We also demonstrate that a ground connec- tion upstream of the emitter electrode can be used to advantage, with a conductive solvent system, to increase the total current at the emitter electrode by at least an order-of-magnitude. Furthermore, by altering the electrical resistance in this upstream current loop (e.g., by altering the length of the connecting tubing between the emitter electrode and the ground connection) it is possible to "dial-in" the current magnitude in this portion of the circuit and change the extent of electrolysis and the distribution of oxidation products observed. Thus, the combination of a PFT electrode emitter and an adjustable upstream current loop in the ES circuit overcomes both the current limit and mass transport limit to efficient analyte oxidation in the ES emitter at flow rates greater than a few tens of microliters per minute. The capabilities of this system are demonstrated with flow injection, continuous infusion, and on-line HPLC separations of model compounds.

\section{Experimental}

\section{Samples and Reagents}

Reserpine (Aldrich, Milwaukee, WI) solutions were prepared in 50/50 (vol/vol) water (Milli-Q, Bedford, MA) and acetonitrile (Burdick and Jackson, Muskegon, MI) containing $5.0 \mathrm{mM}$ ammonium acetate $(99.999 \%$, Aldrich) and $0.75 \%$ (by volume) acetic acid (PPB/Teflon grade, Aldrich). The ferroceneboronate derivative of pinacol was synthesized as described elsewhere [8]. Stock solutions and dilutions of this analyte were prepared in acetonitrile/water $(80 / 20 \mathrm{vol} / \mathrm{vol})$ containing either $200 \mu \mathrm{M}$ or $1.0 \mathrm{mM}$ ammonium acetate.

\section{ES-MS}

Experiments were performed on a PE Sciex API 165 single quadrupole mass spectrometer (MDS Sciex, Concord, Ontario, Canada). A HP 1090 HPLC system or syringe pump was used to deliver solvent and analyte solutions to the ion source. On-line HPLC of the ferroceneboronate derivative was performed at $50 \mu \mathrm{L} / \mathrm{min}$ using a $1.0 \mathrm{~mm}$ i.d. $\times$ $15 \mathrm{~cm}$ long PAH Hypersil column (5 $\mu \mathrm{m}$ particles, $120 \AA$ pore size, Keystone Scientific, Inc., Bellefonte, PA) with a mobile phase comprised of $80 / 20$ acetonitrile/water containing either $200 \mu \mathrm{M}$ or $1.0 \mathrm{mM}$ ammonium acetate. Mass spectra were acquired with the normal TurboIonSpray source in place using either a $3.5 \mathrm{~cm}$ long fused-silica capillary (100 $\mu \mathrm{m}$ i.d., $330 \mu \mathrm{m}$ o.d.) or a $3.5 \mathrm{~cm}$ long platinum spray capillary emitter (100 $\mu$ m i.d., $400 \mu$ m o.d.) as described previously [20] (Figure 1a), or with a porous flow-through electrode emitter (Figure 1b). In typical operation, a $40 \mathrm{~cm}$ long $(100 \mu \mathrm{m}$ i.d. $\times 1 / 16$ in. o.d. $)$ polyetheretherketone (PEEK) tube connected the upstream ground point in the TurbolonSpray source to the emitter electrode.

The porous electrode of the PFT electrode emitter was housed in a cylindrical sandwich assembly comprised of stainless steel inlet and outlet end caps and a PEEK cell 

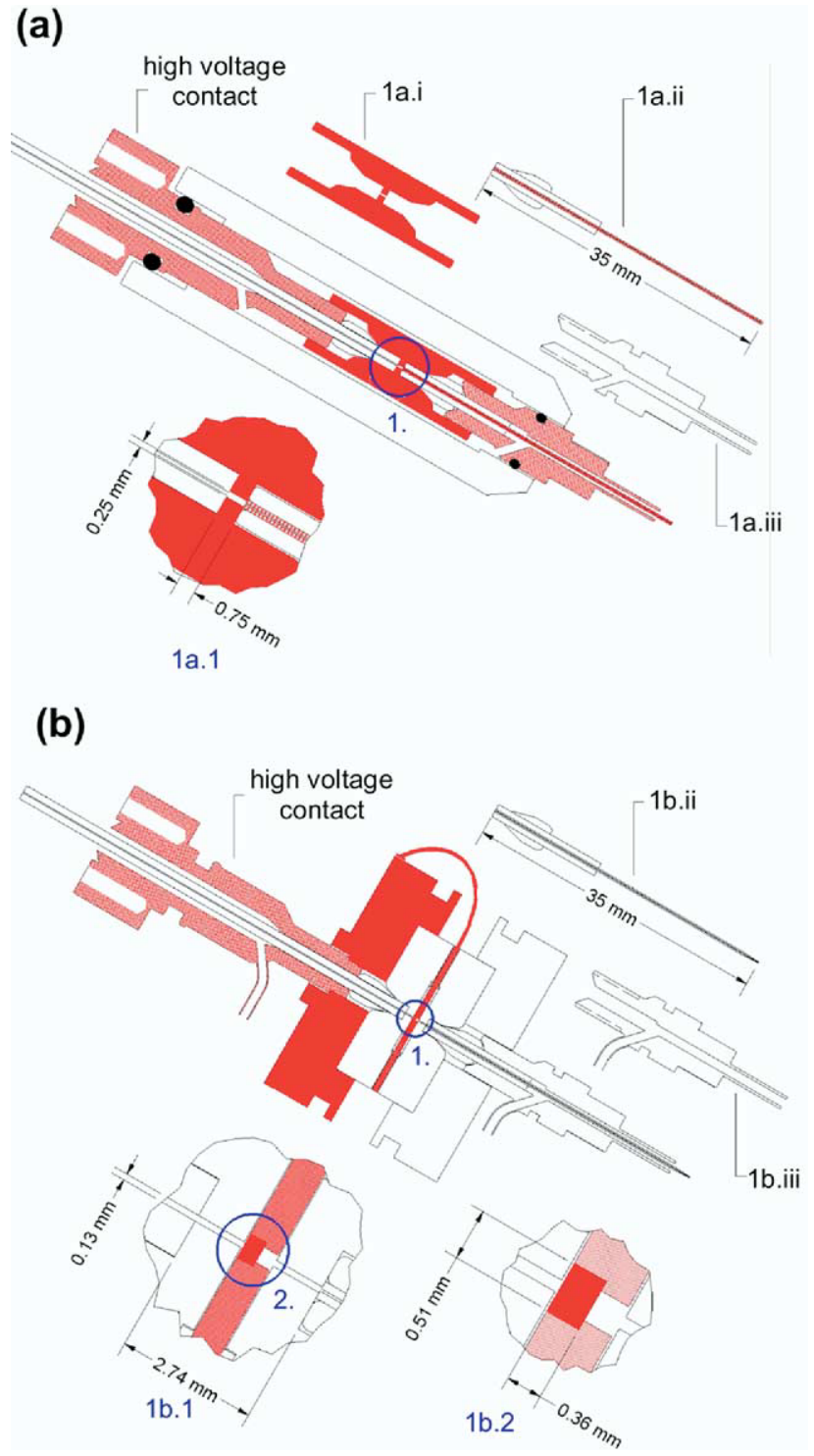

Figure 1. Illustrations of (a) normal TurboIonSpray electrode configuration and (b) porous flow through electrode emitter mounted in TurbolonSpray source: (1a.i) zero-dead volume stainless steel coupler; (1a.ii) electrospray emitter capillary (platinum or fused silica); (1a.iii) nebulizer capillary assembly; (1a.1) expanded view of dimensioned fluid passage through coupler; (1b.ii) fused silica electrospray emitter capillary; (1b.iii) nebulizer capillary assembly modified with sidearm adapter; (1b.1) expanded view of dimensioned fluid pathway through PFT electrode assembly; (1b.2) expanded view of $1 b .1$ showing PFT electrode details. High voltage contact indicated by red shading. With the non-conductive fused silica emitter in (a), high voltage contact to solution occurred only at the stainless steel coupler.

body (Figure 1b). The electrode was composed of porous graphitic carbon (PGC) $0.508 \mathrm{~mm}$ diameter $\times 0.36 \mathrm{~mm}$ thick (40\% total porosity, $99 \%$ open porosity with a nominal pore size of $0.8 \mu \mathrm{m})$. The calculated surface area of the electrode was $170 \mathrm{~mm}^{2}$. The surface and cross section of the porous electrode were characterized by field emission scanning electron microscopy operating at an acceleration voltage of $30 \mathrm{kV}$ (Topcon Technologies, Inc., Paramus, NJ). This electrode assembly was mounted in the TurboIonSpray source by simple exchange of the zero-dead volume union, nebulizer tube, and emitter capillary assembly that connects the solution flow into the source at a stainless steel male 10-32 fitting (Figure 1a). This fitting is also the point of high voltage (HV) electrical connection to the emitter electrode in this and the unmodified TurboIonSpray source. Fluid flow through the cell was along the radial axis ( $0.127 \mathrm{~mm}$ i.d. passage) and passed directly through the working electrode located at half cell height. The inner dimensions of the electrode assembly afforded a nominal swept volume of $0.1 \mu \mathrm{L}$. The solution exited the electrode and was sprayed through a $3.5 \mathrm{~cm}$ length of $50 \mu \mathrm{m}$ i.d., $360 \mu \mathrm{m}$ o.d. fused silica capillary (70 nL volume) with a Taper Tip (New Objective, Inc, Woburn, MA) held in place using appropriate ferrules and a nebulizer tube nut (Figure 1b). Nebulizing gas flow connection was made by attaching a bypass line $(1 / 16$ in. o.d. Teflon tubing ) from a capillary sidearm epoxied into the nebulizing gas inlet on the fitting where the HV connection was made over to a capillary sidearm epoxied into the nebulizer nut (Figure $1 \mathrm{~b}$ ). To protect the PFT electrode emitter from plugging, a precolumn filter ( 0.5 $\mu \mathrm{m}$ frit) was placed in the flow stream in all experiments. To maintain optimum oxidation efficiency in positive ion mode the PFT electrode was periodically maintained at high negative potential for $30 \mathrm{~s}$ with the solvent system flowing. This procedure, which was more often necessary in experiments using continuous infusion or large volume injections than in flow injection or on-line HPLC separations, reactivated the electrode surface.

The ES current was measured on the mass spectrometer side of the circuit by grounding the curtain plate (normally $1.0 \mathrm{kV}$ ) of the mass spectrometer through a Keithley model 610C electrometer (Cleveland, $\mathrm{OH}$ ) and lowering the emitter voltage by $1.0 \mathrm{kV}$. The spray capillary was moved laterally beyond the sampling orifice so all of the charged droplets impacted the curtain plate. The current in the back loop was measured by connecting the upstream ground connection to ground through the electrometer with no other conditions altered.

Correction of peak abundances in the ES mass spectra for isotopic overlaps was carried out by first calculating the theoretical isotope pattern using IsoPro 3.0 software [21]. The contribution of the lowest $\mathrm{m} / \mathrm{z}$ ion in a peak cluster to the abundance of each of the other peaks in the cluster was calculated and subtracted from the abundance value for those respective peaks in the original data. These corrected intensities were then used for the calculation of the contribution of the species $1 \mathrm{~m} / \mathrm{z}$ higher, and so on.

\section{Results and Discussion}

Figure 1 shows illustrations of the three ES emitter assemblies used in this work. The emitter arrangement making use of a fused silica spray capillary with a HV contact to solution at an upstream stainless steel coupler has previously been shown [20] to minimize analyte oxidation at solution flow rates less than $30 \mu \mathrm{L} / \mathrm{min}$ (Figure 1a). This 
electrode arrangement limits mass transport of the analyte to the relatively small emitter electrode surface (i.e., the internal walls of conductive coupler). In comparison, when this fused silica capillary was replaced with one fabricated from stainless steel (the commercial version of the source), or preferably platinum (Figure 1a), analyte oxidation was substantially enhanced, particularly at low flow rates $(<15 \mu \mathrm{L} / \mathrm{min})$. This result was explained on the basis of the increased surface area of the electrode, which in turn allowed for increased analyte flux to the electrode. In the case of platinum, additional benefit was gained because none of the ES current was consumed via electrode corrosion as was possible when using the stainless steel electrode [22]. With either electrode arrangement, analyte oxidation was nearly insignificant at solution flow rates of $30 \mu \mathrm{L} / \mathrm{min}$ or greater [20].

The inefficiency of the fused silica capillary and platinum capillary electrode emitter arrangements for analyte oxidation at high solution flow rates is illustrated here by the reserpine data in Figure 2a and b. Reserpine is commonly used to test the specifications of ES mass spectrom-
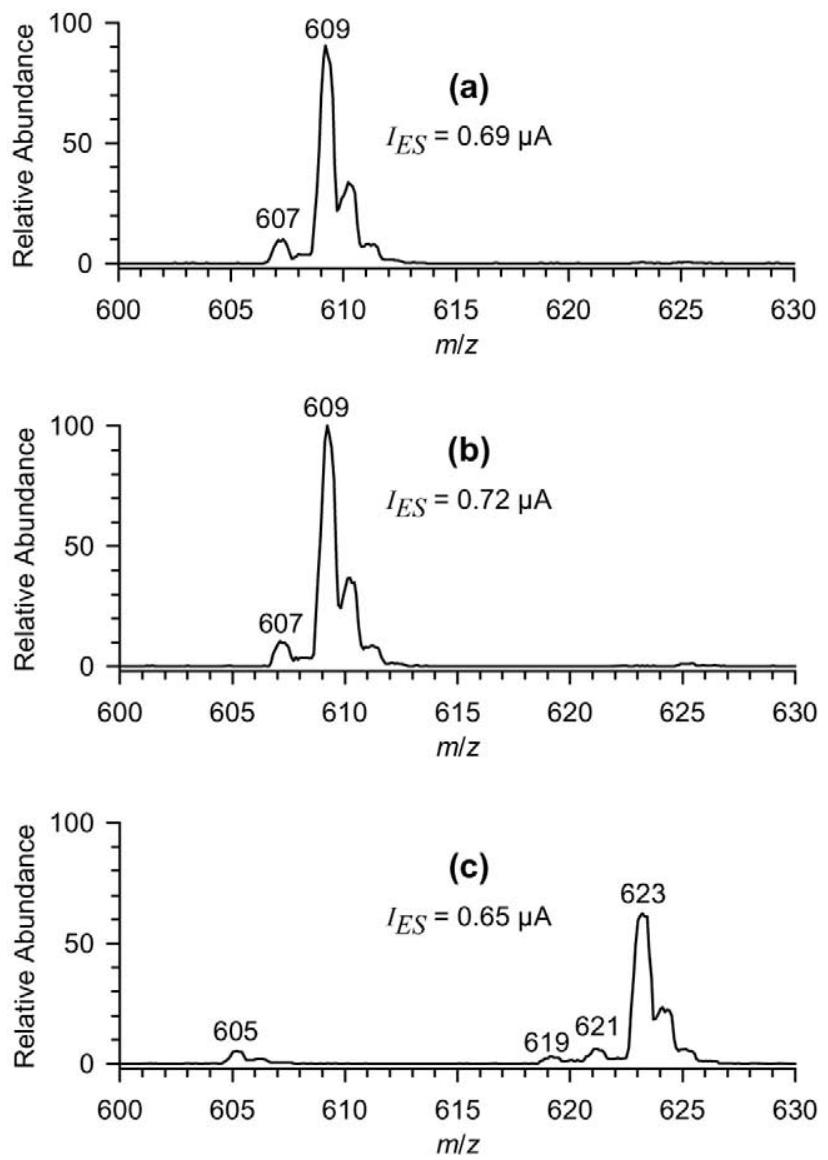

Figure 2. Background subtracted, averaged ES mass spectra obtained from a $1 \mu \mathrm{L}$ injection of a $20 \mu \mathrm{M}$ solution of reserpine (20 pmol) at a flow rate $50 \mu \mathrm{L} / \mathrm{min}$ using (a) a fused silica emitter, (b) a platinum capillary electrode emitter, and (c) a PFT electrode emitter with the upstream ground point in the circuit connected in each case. Sample and eluant composition 50/50 (vol/vol) water/ acetonitrile, $5.0 \mathrm{mM}$ ammonium acetate, $0.75 \%$ by volume acetic acid.
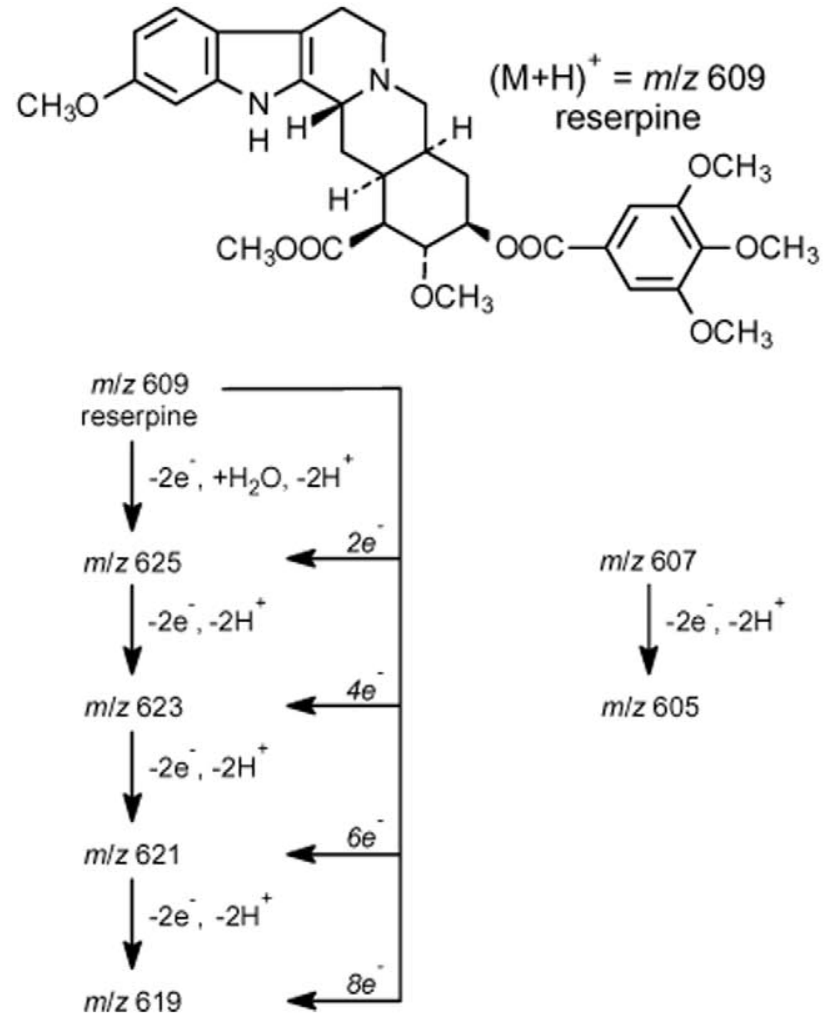

Scheme 1. Reserpine structure, proposed oxidation pathways and ions observed.

eter systems and is relatively easy to oxidize to a number of products via a complex, not yet fully elucidated, reaction sequence (Scheme 1) [13, 23-26]. In our experiments, $1.0 \mu \mathrm{L}$ of a $20 \mu \mathrm{M}$ solution of reserpine (20 pmol) was injected into a flowing stream $(50 \mu \mathrm{L} / \mathrm{min})$ of the same solvent composition as the sample. The base peak in these spectra at $\mathrm{m} / \mathrm{z} 609$ corresponded to the protonated molecule of reserpine. A much less abundant peak at $\mathrm{m} / \mathrm{z} 607$ was an auto-oxidation product of reserpine present in the solution. This species was formed upon aging of the reserpine solution on the lab bench over the course of $24 \mathrm{~h}$ prior to the analysis. No other peaks that could be attributed to oxidation of reserpine were observed. The situation was dramatically different when the same flow injection experiment was performed with the PFT electrode emitter as illustrated by the data in Figure 2c. The base peak was observed at $m / z 623$. This peak corresponds in mass to the product of a $4 \mathrm{e}^{-}$transfer reaction tentatively assigned as 1-hydroxy-3,4-dehydroreserpine (Scheme 1) [23]. The minor peak at $\mathrm{m} / \mathrm{z} 605$ corresponds to a $2 \mathrm{e}^{-}$ oxidation product of the species initially observed at $\mathrm{m} / \mathrm{z}$ 607. Those peaks at $\mathrm{m} / \mathrm{z} 621$ and 619 can be attributed to products of $6 \mathrm{e}^{-}$and $8 \mathrm{e}^{-}$oxidation of reserpine, respectively. No peak corresponding to the parent molecule was observed indicating $100 \%$ oxidation efficiency.

The efficient reserpine oxidation observed with the PFT electrode emitter compared to the tubular electrode arrangements was attributed to the enhanced mass transport to the electrode surface with the PFT electrode 
design. The ES currents measured at the counter electrode on the mass spectrometer side of the ES circuit among the three experiments did not differ by more than $10 \%\left(I_{E S}=0.69,0.72\right.$, and $0.65 \mu \mathrm{A}$ for the fused silica capillary, platinum capillary electrode, and PFT electrode, respectively) indicating this parameter was probably not a factor. The calculated charge, $Q$, required for $4 \mathrm{e}^{-}$oxidation of $20 \mathrm{pmol}(1 \mu \mathrm{L} \times 20 \mu \mathrm{M})$ of reserpine (analyte amount $(\mathrm{mol}) \times$ Faraday constant $\left(9.65 \times 10^{4} \mathrm{C} / \mathrm{mol}\right) \times n$ (number of electrons) $)$ in the flow injection peak (ca. $29 \mathrm{~s}$ wide) is $7.7 \mu \mathrm{C}$. This is substantially less than the theoretically available charge of ca. 19-21 $\mu \mathrm{C}$ [peak width $(\mathrm{s}) \times I_{E S}(\mathrm{C} / \mathrm{s})$ ] again indicating that the electrolysis efficiency would not be expected to be current limited with any of the three emitter electrode arrangements. Note that there was substantial peak dispersion owing to the length of tubing (ca. $1 \mathrm{~m}$ ) between the HPLC injector and the ion source of the mass spectrometer. However, even for an ideal $1.0 \mu \mathrm{L}$ volume injection profile (1.2 $\mathrm{s}$ wide peak), the reaction $\left(\leq 4 \mathrm{e}^{-}\right.$transfer $)$would not have been significantly current limited because the magnitude of the current at the emitter was actually substantially larger than indicated by the magnitude of $I_{E S}$ alone (see continuous infusion data below).

The efficacy of analyte transport to the emitter electrode can be expected to dramatically differ among the three emitter electrode arrangements investigated with the PFT electrode emitter being most efficient. Complex numerical solutions to mass transport in tubular electrodes have appeared in the literature [27-30], but for the purposes of this work a simple qualitative comparison of the mass transport phenomena among the three emitter geometries can be used to illustrate the differences. The geometry of the emitter electrode in all three of the arrangements shown in Figure 1 (Case 1: fused silica capillary with conductive coupler electrode; Case 2: platinum capillary electrode; Case 3: PFT electrode) can be visualized in a radial coordinate system where the radius of the electrode is $R$ and the center of the coordinate system lies in the center of the electrode (Figure 3). We assume that Hagen-Poiseuille behavior is maintained during transit of analyte molecules through

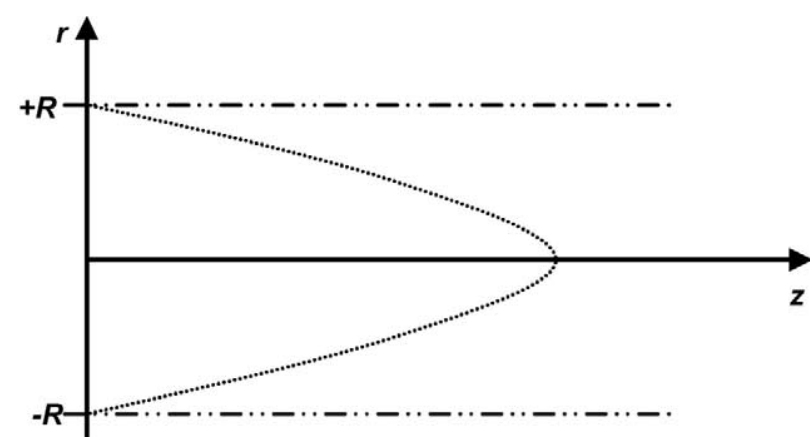

Figure 3. Diagram of a generic tubular channel electrode showing the coordinate system and parabolic fluid flow profile encountered in Hagen-Poiseuille flow behavior. the electrode. That is, the flow adopts a parabolic flow profile where there is a no-slip boundary at the electrode surface and the highest linear flow velocity is observed in the center of the tube due to the relatively low volumetric flow rate, $v_{f}$, through the electrode and the dimensions of the flow path. Electrolysis of an electroactive analyte, $i$, occurs during the residence period, $\tau$, in the tubular electrode. When the emergent solution is completely denuded of $i$ the process is 100\% efficient. In all three of the emitter electrode arrangements, flux of $i$ to the solution/electrode interface occurs through convective-diffusive mass transport according to eq 1

$$
J_{i}=-D_{i} \nabla C_{i}+C_{i} v_{z}
$$

where $J_{i}$ is the flux of analyte $i$ due to diffusion $\left(D_{i}\right.$ is the diffusion coefficient of $i$ and $C_{i}$ is the concentration of $i$ ) and convection $\left(v_{z}\right.$ is the linear velocity along the $\mathrm{z}$ axis) of $i$. To simplify the model, we assume that the rate of mass transport due to diffusion is much slower than that due to convection in the $\mathrm{z}$ coordinate. This is a valid assumption if the flow rate is fast and the electrode is short, so that diffusion along the $\mathrm{z}$ coordinate to the electrode is negligible. In the $\mathrm{r}$ direction, mass transport takes place by diffusion, and under the conditions of laminar flow, convection in the r direction does not take place.

A simple means to then qualitatively compare relative mass transport behavior between the three emitter electrode geometries is performed by comparing the nominal length, $l_{i}$, over which analyte $i$ would diffuse in each configuration during $\tau$ and normalizing that distance by the electrode radius. We evaluated $l_{i}$ by employing the Einstein equation (eq 2)

$$
l_{i}=\sqrt{2 D_{i} \tau_{i}}
$$

to each of the assembly configurations. $\tau_{i}$ was determined by the ratio of the electrode length, $L$, and the mean solution velocity, $U$, where $U$ was obtained by finding the mean velocity of the parabolic flow profile, $v_{z}(r)$ (eqs 3 and 4 ).

$$
\begin{aligned}
& v_{z}(r)=\frac{2\left(R^{2}-r^{2}\right)}{\pi R^{4}} v_{f r} \\
& U=\frac{1}{2 R} \int_{-R}^{R} v_{z}(r) d r=\frac{4}{3 \pi R^{2}} v_{f}
\end{aligned}
$$

Determining $\tau_{i}$ and in turn $l_{i}$ for Cases 1 and 2 is straightforward and values are listed in Table 1 as a function of $v_{f}$. However, in Case 3 the electrode is comprised of a series of ca. $55 \times 10^{6}$ pores of nominal $0.8 \mu \mathrm{m}$ diameter as shown by the scanning electron micrographs in Figure 4. To simplify the calculation, we assumed that all pores accessible to solution were linear. This assumption most probably underestimated $\tau_{i}$ as the pores did not appear to be 

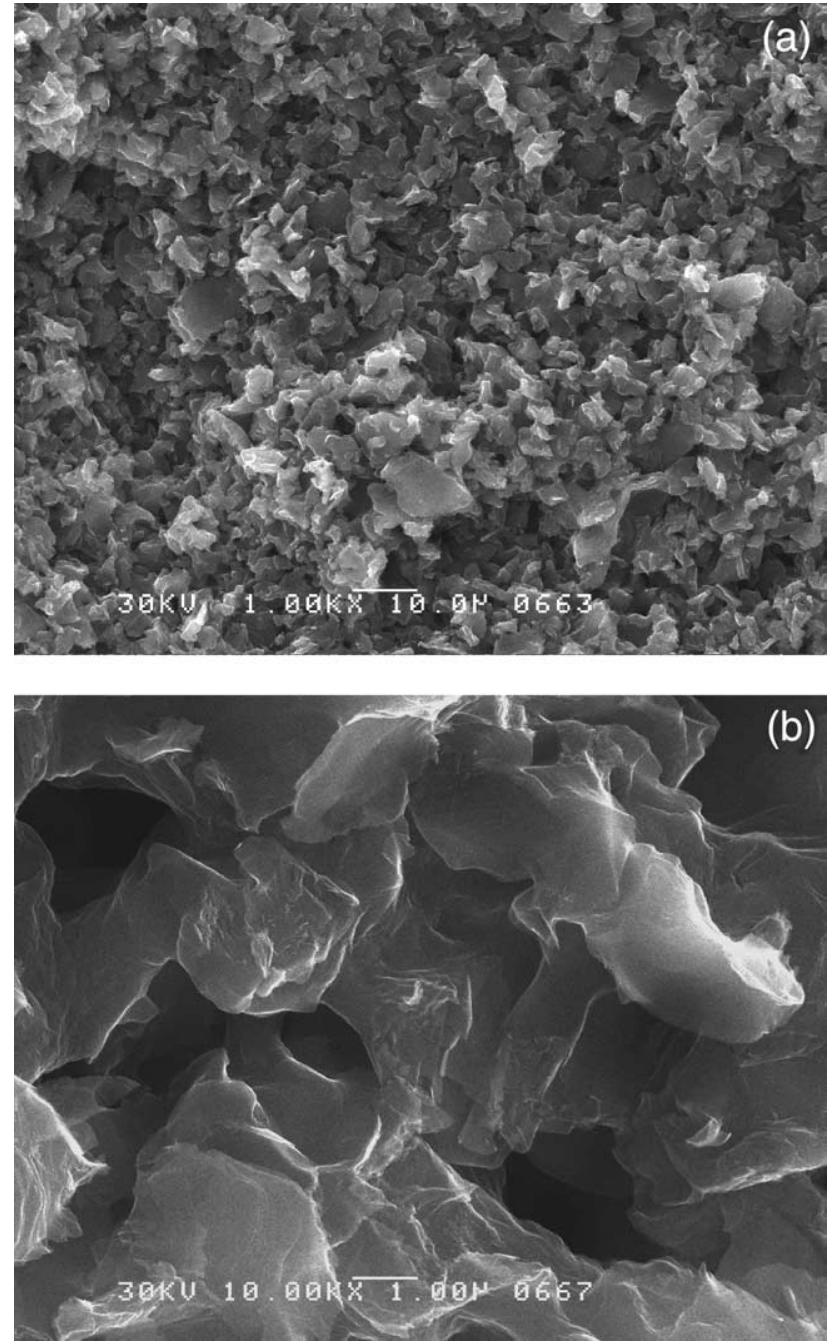

Figure 4. Field emission scanning electron micrographs of the porous carbon surface. Scale bar is (a) $10 \mu \mathrm{m}$ and (b) $1 \mu \mathrm{m}$.

linear (based on the scanning electron microscopy data presented in Figure 4). We further assumed that $v_{f}$ was evenly split between each of the accessible pores and that these pores were normal to solution flow. The results obtained following this protocol are also tabulated in Table 1.

In this crude approach at comparing the probability that an analyte molecule will encounter the electrode surface in each of the three emitter configurations, we make use of the dimensionless ratio $l_{i} / R$-the theoretical diffusion distance of analyte $i$ during $\tau_{i}$ normalized to the electrode radius. It is observed that $l_{i} / R$ for the PFT electrode emitter (Case 3) is ca. 26 times larger than for the platinum capillary electrode emitter (Case 2), which in turn is ca. 7 times larger than that for fused silica capillary with conductive coupler electrode (case 1). These calculations indicate that mass transport in the PFT should be at least an order of magnitude more efficient than either of the other two capillary emitter electrode geometries at all flow rates. The relative efficiency would appear even greater for the PFT emitter if we had not made the 
generous, but unlikely, assumption that analyte oxidation could take place over the full $3.5 \mathrm{~cm}$ length of the platinum capillary $[16,31]$. In sum, these approximate mass transport calculations support enhanced mass transport as the reason for the substantially greater oxidation efficiency observed with the PFT electrode emitter experimentally.

Although limitations to electrolysis efficiency owing to mass transport were relieved with the PFT electrode emitter, the typical magnitudes of $I_{E S}$, even with substantial added electrolyte $\left(I_{E S}<1.0 \mu \mathrm{A}\right)$ [19], were such that analyte oxidation would likely be current limited when carrying out continuous infusion experiments. In the small volume flow injection experiments described above, the substantial peak dispersion lowered the analyte concentration below that of the bulk solution concentration of the volume injected. That was not the case with large volume flow injection or continuous infusion experiments where the concentration of the analyte entering the ion source was the same as the bulk solution concentration. This limitation was apparent, particularly for multiple electron transfer reactions, when calculating the required current for $100 \%$ oxidation efficiency using eq 5

$$
I=n F v_{f} C_{i}
$$

where $n$ is the molar equivalent of electrons involved in the redox reaction of analyte $i$ and $F$ is the Faraday constant. For example, using eq 5, it was calculated that complete oxidation of reserpine in a $20 \mu \mathrm{M}$ solution flowing through the emitter at $50 \mu \mathrm{L} / \mathrm{min}$ for reactions involving $2 \mathrm{e}^{-}, 4 \mathrm{e}^{-}, 6 \mathrm{e}^{-}$, or $8 \mathrm{e}^{-}$would require currents of 3.2, 6.4, 9.6, and $12.8 \mu \mathrm{A}$, respectively. These calculated current magnitudes for $100 \%$ oxidation efficiency are roughly a factor of five to twenty times larger than $I_{E S}$ values measured in the experiment with the PFT emitter shown in Figure 2c.

Even so, as illustrated by the mass spectra in Figure 5, the efficiency of the PFT emitter in oxidizing reserpine during continuous infusion (provided by a large volume injection) was $100 \%$ at $50 \mu \mathrm{L} / \mathrm{min}$. The spectra in Figure $5 \mathrm{a}$ and $\mathrm{c}$ were obtained by large volume injection $(150 \mu \mathrm{L})$ of $20 \mu \mathrm{M}$ reserpine using a PFT electrode emitter and the platinum capillary electrode, respectively. Each spectrum was recorded during the extended plateau region of the injection (analyte concentration was $20 \mu \mathrm{M}$ ). In both cases, the normal grounding point in the ES ion source circuit was made $40 \mathrm{~cm}$ upstream of the emitter electrode. The base peak at $m / z 609$ in the spectrum obtained with the platinum capillary electrode emitter corresponded to protonated reserpine with little if any ES-formed oxidation products observed (Figure 5c). All of the reserpine was oxidized to form a number of different products via multiple electron transfer reactions when using the PFT electrode emitter (Figure 5a, see also Scheme 1). Because $I_{E S}$ was measured as only $0.49 \mu \mathrm{A}$ in this experiment, the extent of oxidation observed in the spectrum in Figure 5a was far more than would be expected (e.g., $3.2 \mu \mathrm{A}$ required just for complete $2 \mathrm{e}^{-}$oxidation).
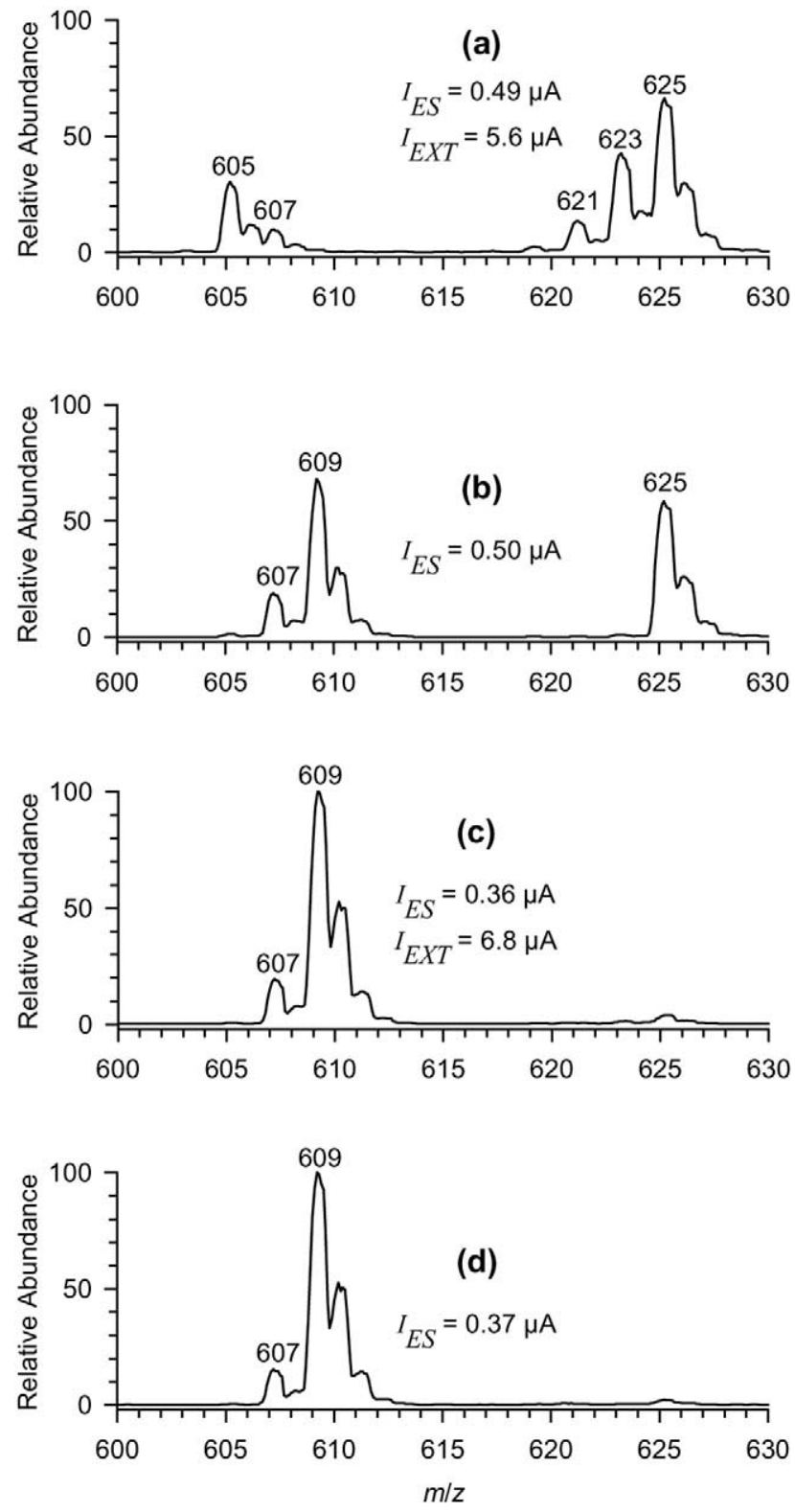

Figure 5. Background subtracted, averaged ES mass spectra acquired at the plateau region of a large volume injection $(150 \mu \mathrm{L})$ of a $20 \mu \mathrm{M}$ solution of reserpine at a flow rate $50 \mu \mathrm{L} / \mathrm{min}$ using a porous flow-through electrode emitter (a) with an upstream ground and (b) without an upstream ground and using a platinum capillary electrode emitter (c) with an upstream ground and (d) without an upstream ground Solution composition 50/50 ( $\mathrm{vol} / \mathrm{vol}$ ) water/acetonitrile, $5.0 \mathrm{mM}$ ammonium acetate, $0.75 \%$ by volume acetic acid.

The explanation for this observation was the additional current at the emitter electrode attributable to an upstream current loop in the ES circuit (Figure 6). In ES ion source configurations in which the emitter electrode is floated at high absolute voltage, relative to the counter electrode on the mass spectrometer side of the circuit, there is often either a discrete (for safety reasons) or adventitious ground point in the circuit upstream of this high voltage contact $[32,33]$. As a result, there is an upstream current loop in the ES circuit that 


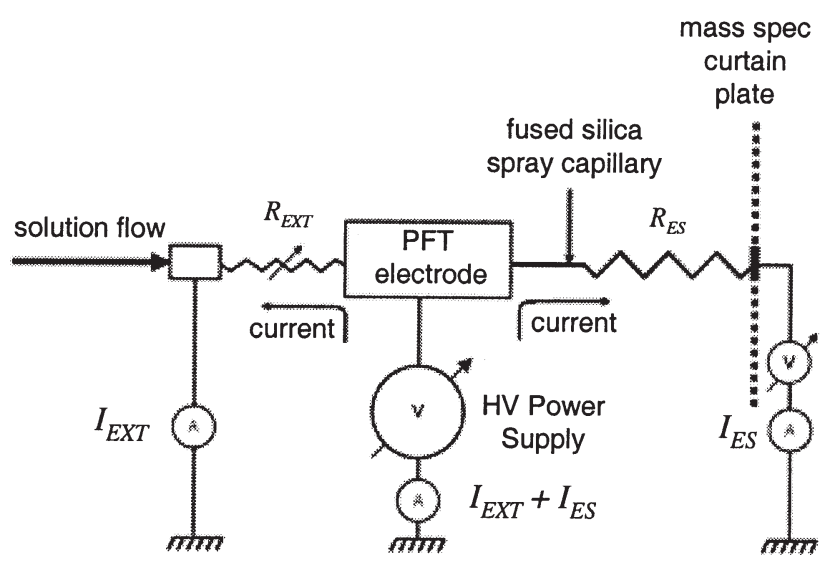

Figure 6. Diagram of electrical circuit for ES ion source showing external upstream current loop. See text for details.

has a common return with the counter electrode on the spray side of the circuit. As named by Konermann et al. [33], these two current loops in the circuit and their respective magnitudes are the ES current loop, $I_{E S}$, formed between the emitter electrode and the mass spectrometer as counter electrode and the external upstream current loop, $I_{E X T}$, formed between the emitter electrode and an upstream ground point in the solution flow stream. The sum of these two currents equals the total current (anodic in this case) at the emitter electrode $\left(I_{T O T}=I_{E S}+I_{E X T}\right)$.

The magnitude of the current in this external, upstream circuit will be a function of the voltage drop between the emitter and ground point and the resistance between these two electrodes. The resistance, $R_{E X T}$, is a function of the solution conductivity, the diameter, and the length of the transfer line between the electrodes $[33,34]$. We found that under the conditions of the experiment in Figure 5, the $I_{E X T}$ was about $6.8 \mu \mathrm{A}$ for the platinum electrode emitter source and $5.6 \mu \mathrm{A}$ for the PFT electrode emitter source. Thus, $I_{T O T}$ was about 7.2 and $6.1 \mu \mathrm{A}$ respectively for the two emitter arrangements. Given efficient mass transport to the electrode surface one would expect that complete oxidation involving up to $4 \mathrm{e}^{-}$would be possible with the platinum capillary. Observing no reserpine oxidation when using the platinum capillary electrode emitter strengthens the argument that inefficient mass transport limits the oxidation efficiency with this electrode geometry (Figure 5c). For the PFT electrode emitter, $I_{T O T}$ was 6.1 $\mu \mathrm{A}$ which was slightly less than enough current for total $4 \mathrm{e}^{-}$oxidation. We saw complete oxidation of the parent molecule with the products distributed among those formed by $2 \mathrm{e}^{-}, 4 \mathrm{e}^{-}$, and $6 \mathrm{e}^{-}$transfer (Figure $5 \mathrm{a}$ ).

The current in the external upstream loop was confirmed to be responsible for the greater extent of oxidation than expected by repeating the experiments leading to the data in Figure $5 \mathrm{a}$ and $\mathrm{c}$ with the normal upstream ground point in the ES source removed (Figure $5 b$ and $d$ ). When this ground point was removed, a different ground point at some position substantially further upstream (e.g., at the HPLC) completed the circuit. Because of the increased resistance $R_{E X T}$, owing to the longer transfer line to the next ground point (ca. $1.5 \mathrm{~m}$ of $100 \mu \mathrm{m}$ i.d. tubing), the magnitude of the current in this circuit must be substantially lower, but it was not measured. The spectrum in Figure 5b illustrates the lower efficiency of reserpine oxidation using the PFT electrode emitter without the normal upstream ground. The base peak in the spectrum corresponds to protonated reserpine at $\mathrm{m} / \mathrm{z} 609$ with the only oxidation product observed being that of a $2 \mathrm{e}^{-}$oxidation $(\mathrm{m} / \mathrm{z} 625)$. In the case of the platinum capillary electrode emitter (Figure $5 d$ ), there was no effect on the appearance of the mass spectrum by removing the upstream ground loop. This observation was again consistent with the oxidation being limited by inefficient mass transport to the platinum capillary electrode rather than being current limited.

On the basis of the results in Figure $5 a$ and $b$, one can anticipate the potential analytical benefit of manipulating the magnitude of $I_{E X T}$ to control the extent of multiple electron transfer oxidation reactions at the emitter electrode. The magnitude of $I_{E X T}$ can be simply altered by changing $R_{E X T}[33,34]$. Figure 7 shows the plots of the abundance of protonated reserpine and the various reserpine oxidation products as a function of $I_{E X T}$, which was controlled by varying $R_{E X T}$ by changing the length of the connecting tubing $(100 \mu \mathrm{m}$-id.) from the emitter (normally $40 \mathrm{~cm}$ ) to the upstream ground point. The longer this tubing the greater the $R_{E X T}$, and therefore, the lower the $I_{E X T}$. The point marked $I_{E X T}=0 \mu \mathrm{A}$ indicates no discrete

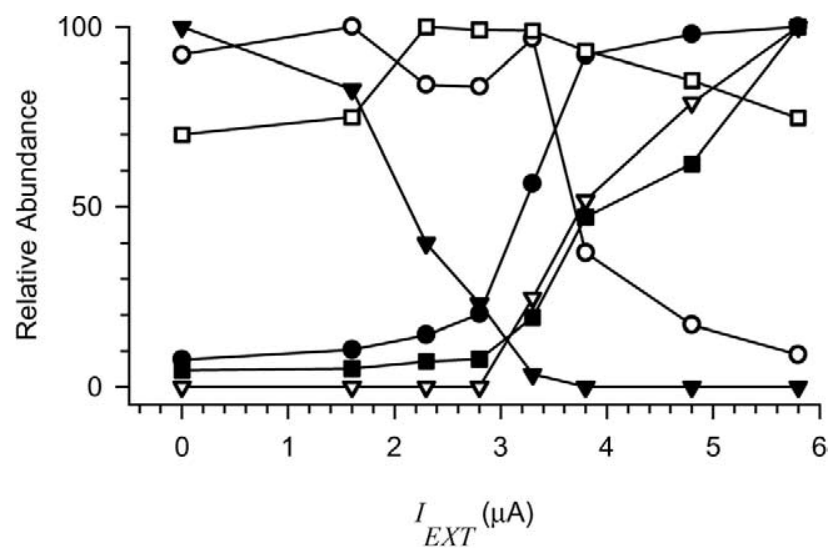

Figure 7. Relative abundance of the protonated molecule of reserpine at $\mathrm{m} / \mathrm{z} 609(\boldsymbol{\nabla})$ and the major products of reserpine oxidation, viz., $m / z 605(\bullet), m / z 607(\bigcirc), m / z 621(\nabla), m / z 623(\square)$, and $m / z 625$ ( $\square$ ) as a function of the current, $I_{E X T}$, measured in the upstream current loop. $I_{E X T}$ was varied by changing the resistance of the upstream loop by changing the length of the connecting tubing between the emitter electrode and the upstream ground contact. Data obtained using large volume injections (150 $\mu \mathrm{L})$ of 20 $\mu \mathrm{M}$ reserpine at $50 \mu \mathrm{L} / \mathrm{min}$ in $50 / 50(\mathrm{vol} / \mathrm{vol})$ acetonitrile/water containing $5.0 \mathrm{mM}$ ammonium acetate and $0.75 \%$ by volume acetic acid. Spectral data plotted is taken from plateau region of injection profile. Peak abundances were corrected for isotopic overlap. The plot for each $\mathrm{m} / \mathrm{z}$ peak was normalized with respect to the largest signal for that particular species. 
ground was made upstream (system grounded at HPLC pumps with ca. $1.5 \mathrm{~m}$ of $100 \mu \mathrm{m}$ i.d. tubing between emitter electrode and the ground point); however, it may be that there was some small magnitude adventitious current. The largest value of $I_{E X T}$ was measured with the normal source upstream ground arrangement. As with the data shown previously, without the upstream current loop in the system, there is still significant oxidation of reserpine evidenced by the appearance of peak at $\mathrm{m} / \mathrm{z} 625$, because of the efficient mass transport and the substantial magnitude of $I_{E S}($ ca. $0.5 \mu \mathrm{A})$. However, the extent of oxidation was substantially less than $100 \%$. Calculations show that in fact a current magnitude of about $3.2 \mu \mathrm{A}$ would be necessary for complete conversion to products requiring a $2 \mathrm{e}^{-}$transfer process and $6.4 \mu \mathrm{A}$ required for complete oxidation to the $4 \mathrm{e}^{-}$oxidation products. As the plots show, almost complete diminution of the reserpine signal was observed at $I_{E X T}=3.3 \mu \mathrm{A}$ as would be expected and the spectrum was dominated by $2 \mathrm{e}^{-}$and $4 \mathrm{e}^{-}$reaction products at this current. These data illustrate that $R_{E X T}$ can be altered to change $I_{E X T}$ in a controlled fashion to "dial-in" the extent of oxidation and the distribution of oxidation products observed.

Data presented above showed that reserpine oxidation was $100 \%$ efficient for flow injection (transient signal) at 50 $\mu \mathrm{L} / \mathrm{min}$ for $20 \mathrm{pmol}$ injected (Figure 2c). Considering the total anodic current at the ES emitter $I_{T O T}$ was about $6 \mu \mathrm{A}$, one would expect that high oxidation efficiency could be maintained at much higher flow rates. This is what was observed as illustrated by the data in Figure 8. The spectrum in Figure 8a shows, as before, that reserpine oxidation was $100 \%$ efficient at a flow rate of $50 \mu \mathrm{L} / \mathrm{min}$ with the product of $4 \mathrm{e}^{-}$oxidation $(\mathrm{m} / \mathrm{z}$ 623) observed as the base peak. Similar efficiency was observed for a flow rate of $200 \mu \mathrm{L} / \mathrm{min}$ (Figure $8 \mathrm{~b}$ ). There was a decrease in the already low abundance peaks at $m / z 621\left(6 \mathrm{e}^{-}\right)$and 619 $\left(8 \mathrm{e}^{-}\right)$relative to their abundance in the spectrum obtained at $50 \mu \mathrm{L} / \mathrm{min}$. At a flow rate of $600 \mu \mathrm{L} / \mathrm{min}$, the oxidation was still $100 \%$ efficient as no peak at $\mathrm{m} / \mathrm{z} 609$ was observed (Figure 8c). However, there was significant change in the distribution of oxidation products observed. The base peak at $m / z 625$ is the $2 \mathrm{e}^{-}$oxidation product. At 800 $\mu \mathrm{L} / \mathrm{min}, \mathrm{m} / \mathrm{z} 609$ was observed at a low relative abundance indicating that the oxidation was no longer $100 \%$ efficient (Figure 8d). The calculated charge, Q, required for $2 \mathrm{e}^{-}, 4 \mathrm{e}^{-}, 6 \mathrm{e}^{-}$, or $8 \mathrm{e}^{-}$oxidation of $20 \mathrm{pmol}$ of reserpine is $3.9,7.7,11.6$, and $15.4 \mu \mathrm{C}$ and the theoretical amount of charge available is $153,56,28$, and $17 \mu \mathrm{C}$ at $50,200,600$, and $800 \mu \mathrm{L} / \mathrm{min}$, respectively. These calculations show that sufficient current for complete multiple electron oxidation (up to at least $8 \mathrm{e}^{-}$) was available at all flow rates $(\mathrm{Q}$ is different at the different flow rates because the analyte peak transit time through the electrode becomes less with increasing flow rate). Thus, it seems reasonable to conclude that the systematic reduction in electrolysis efficiency observed as flow rate increased beyond $200 \mu \mathrm{L} /$ min in these flow injection experiments resulted from diminished mass transport. More efficient oxidation at or above $800 \mu \mathrm{L} / \mathrm{min}$ would require a further improvement
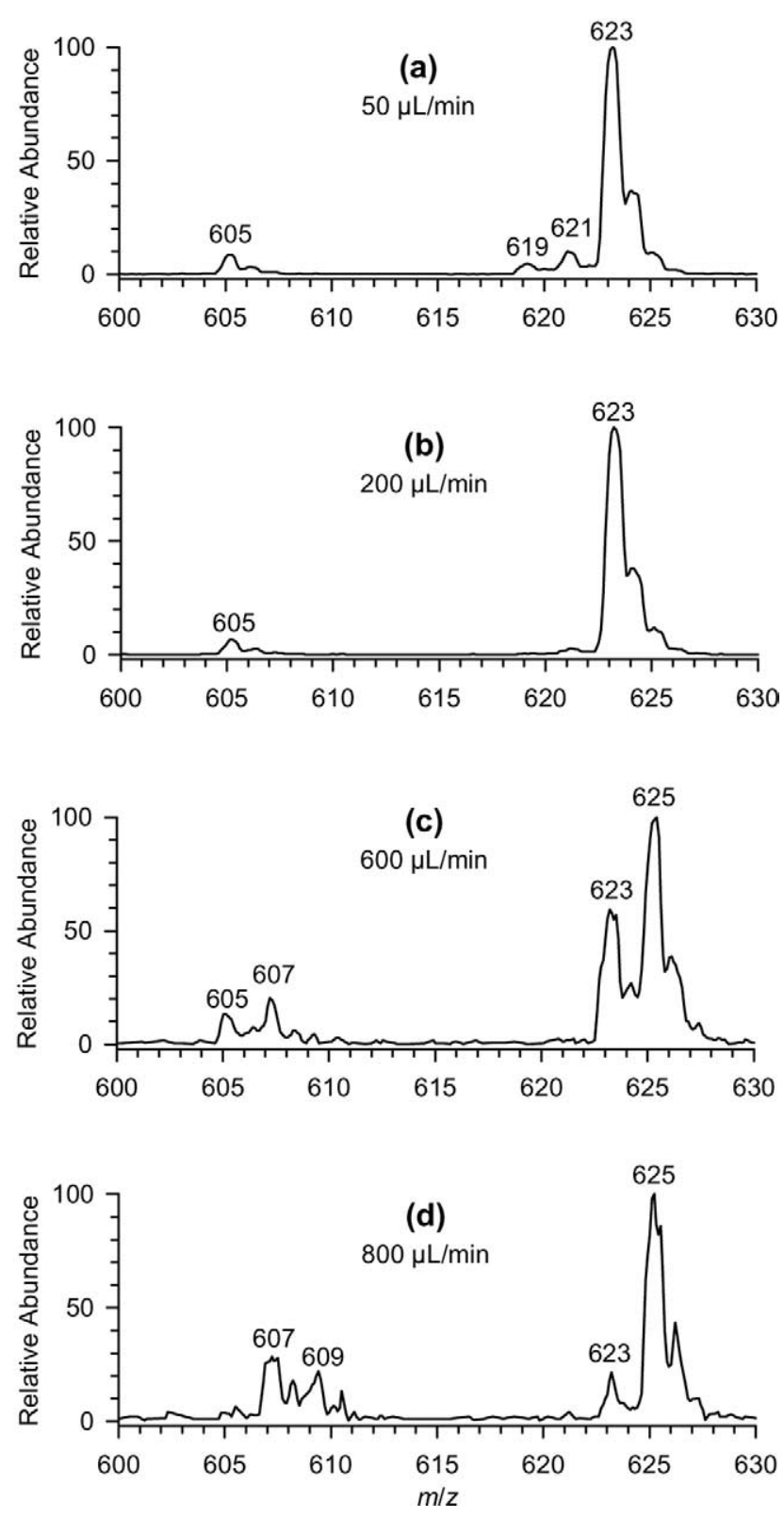

Figure 8. Background subtracted, averaged ES mass spectra of reserpine recorded for flow injections (1.0 $\mu \mathrm{L}$ volume) of a $20 \mu \mathrm{M}$ solution of reserpine $(20 \mathrm{pmol})$ at solution flow rates of (a) 50 $\mu \mathrm{L} / \min$ (b) $200 \mu \mathrm{L} / \min$ (c) $600 \mu \mathrm{L} / \mathrm{min}$, and (d) $800 \mu \mathrm{L} / \mathrm{min}$ using the PFT electrode emitter with the upstream ground point in the circuit connected. Sample and eluant composition 50/50 (vol/vol) water/acetonitrile, $5.0 \mathrm{mM}$ ammonium acetate, $0.75 \%$ by volume acetic acid. $I_{E S}=0.65 \mu \mathrm{A}$ and $I_{E X T}=5 \mu \mathrm{A}$ were near constant over the course of the different flow rates.

in mass transport to the electrode surface, which might be possible through an increase in the length of the PFT electrode.

The reserpine data, as a whole, illustrated that highly efficient analyte oxidation was possible with the PFT electrode emitter and demonstrate the general analytical utility of oxidation at the ES emitter electrode in the study of the products of electrode reactions. One may realize other analytical benefits from the high oxidation 

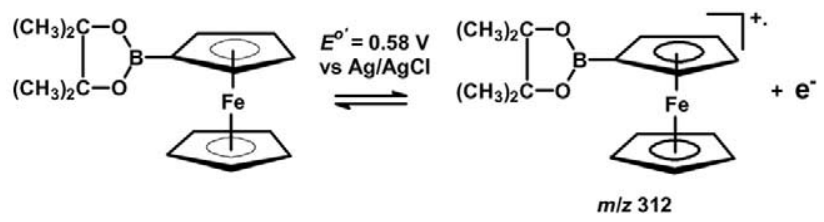

Scheme 2. Oxidation of ferroceneboronate derivative of pinacol.

efficiency of the PFT electrode emitter. Just one example, illustrated here, is the use of the inherent electrolysis process in ES to form radical cations of neutral analytes enabling their detection by ES-MS [7-9]. As demonstrated by Van Berkel et. al. [8], the oxidation of the ferroceneboronate derivative of pinacol (Scheme 2) transforms this electrochemically ionizable derivative into the ES active cation. To demonstrate the utility of the ES oxidation process in a real world analysis scenario, we performed an on-line HPLC/ES-MS separation and detection of the derivative. The mass chromatogram and ES mass spectrum in Figure $9 a$ and $b$, respectively, illustrate the chromatographic peak profile and mass spectrum obtained for this derivative using the PFT electrode emitter. The base peak in the spectrum corresponds to the molecular radical cation at $\mathrm{m} / \mathrm{z} 312$, and the observed isotope pattern is that expected on the basis of the molecular formula of this molecule. The sensitivity and detection levels for this derivative were compared in a separate set of on-line HPLC/ES-MS experiments using the platinum capil-
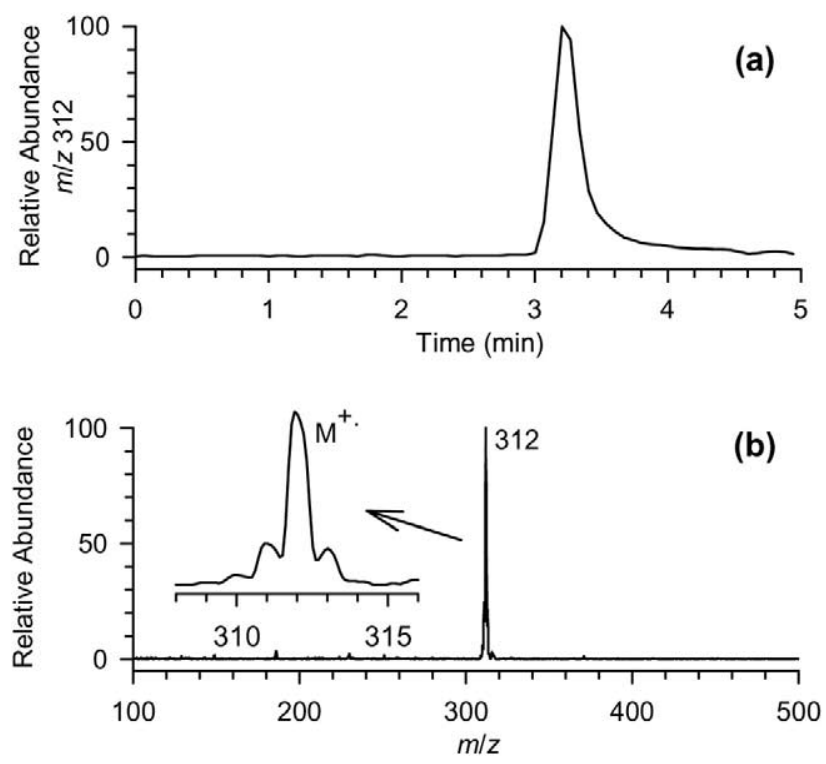

Figure 9. (a) Mass chromatogram obtained from the on-column injection of $4.5 \mathrm{pmol}$ of the ferroceneboronate derivative of pinacol using the PFT electrode emitter. (b) Background subtracted, averaged mass spectrum for the chromatographic peak. Inset shows an expansion of the molecular ion region of the spectrum. Derivative diluted in eluant and injected $(1.0 \mu \mathrm{L})$ onto a $1.0 \mathrm{~mm}$ i.d. $\times 15$ cm-long PAH Hypersil column (5 $\mu$ m particles, $120 \AA$ pore size). Eluant composition 80/20 (vol/vol) acetonitrile/water, $200 \mu \mathrm{M}$ ammonium acetate, flow rate $=50 \mu \mathrm{L} / \mathrm{min} . I_{T O T} \sim 1.6 \mu \mathrm{A}$. lary electrode emitter and PFT electrode emitter systems (Figure 10). A slightly different mobile phase was used over that utilized to obtain the data in Figure 9 and detection was via selected ion monitoring. Comparison of the slopes of the regression lines of the plots of chromatographic peak areas versus derivative amount injected indicates the superior sensitivity of the PFT emitter. The detection levels were as low as $8 \mathrm{fmol}$ injected with the PFT electrode emitter compared with no less than $40 \mathrm{fmol}$ injected with the platinum capillary electrode emitter. For both emitters the precision among replicate sample injections was very good. The detection levels in both cases would scale to considerably lower levels with selected reaction monitoring (SRM) detection as suggested on the basis of previous studies for related derivatives [8].

\section{Conclusions}

The use of a PFT electrode emitter in an ES ion source improves the efficiency of analyte electrolysis over that obtained with a tubular emitter electrode geometry through improved mass transport of the analyte to the electrode surface. An upstream current loop in the ES circuit increases the current magnitude at the emitter electrode by at least an order of magnitude over that available from just the ES current, and therefore, can be used to overcome current limited electrolysis efficiency at high flow rates and high analyte concentrations. This upstream current loop is present many times though not necessarily noted in published work. In our own work, we have often used a syringe pump with an isolated plastic syringe to pump solution into the ion source. This eliminated the back current loop $\left(I_{E X T}=0\right)$ and the total electrolysis current was equivalent to the current measured at the counter electrode on the mass

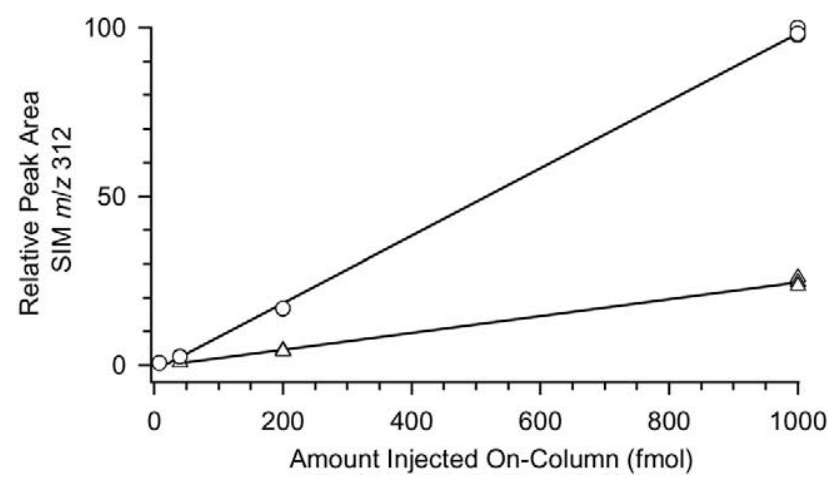

Figure 10. Plots of relative peak areas of the radical cation of the ferroceneboronate derivative of pinacol $(\mathrm{m} / \mathrm{z}$ 312) as a function of the amount injected on-column ( 3 replicate injections at each amount) using either the PFT electrode emitter $(\bigcirc)$ or the platinum capillary electrode emitter $(\triangle)$. Derivative diluted in eluant and injected $(1.0 \mu \mathrm{L})$ onto a $1.0 \mathrm{~mm}$ i.d. $\times 15 \mathrm{~cm}$-long PAH Hypersil column (5 $\mu \mathrm{m}$ particles, $120 \AA ̊$ pore size). Eluant composition $80 / 20$ ( $\mathrm{vol} / \mathrm{vol})$ acetonitrile/water, $1.0 \mathrm{mM}$ ammonium acetate, flow rate $=50 \mu \mathrm{L} / \mathrm{min}$, SIM dwell time $=500 \mathrm{~ms}$. PFT electrode emitter: $I_{T O T} \sim 1.5 \mu \mathrm{A}$; platinum capillary electrode emitter: $I_{T O T} \sim 2.1 \mu \mathrm{A}$. 
spectrometer side of the circuit $\left(I_{T O T}=I_{E S}\right)$. For instrumental configurations that use a grounded emitter electrode arrangement similar to the original Fenn designs [35], the back current loop is not present.

The high electrolysis efficiency afforded by the PFT electrode emitter and the upstream current loop arrangement will enhance the utility of the inherent electrochemistry of the ES ion source for applications such as analyte ionization and detection, the study of electrode reactions, or the creation and study of novel ionic species [5-12]. The relatively simple design and small size of the PFT electrode emitter will allow it to be implemented on many of the commercially available ES ion sources. While the experiments in this work have been limited to analyte oxidation in positive ion mode, we expect similar performance enhancement for analyte reduction in negative ion mode. We demonstrated near $100 \%$ electrolysis efficiency for 20 pmol of reserpine injected (a two electron oxidation) at a solution flow rate approaching $800 \mu \mathrm{L} / \mathrm{min}$. This high electrolysis efficiency was obtained at a flow rate an order-ofmagnitude faster than previously demonstrated with any other ES emitter electrode configuration [7, 19]. A longer PFT electrode than that used in this work might be investigated to extend the high electrolysis efficiency up to $1.0 \mathrm{~mL} / \mathrm{min}$. By changing the resistance in the upstream current loop we were able to alter the current in the upstream loop and gain a measure of control in the extent of the analyte electrolysis. One can envision that this resistance might be altered in the future more conveniently by insertion of a variable resistor to "dialin" the desired current in this current loop. Electrode material is known to have an influence on electron transfer reactions [36] and we previously demonstrated with a planar electrode emitter that the electrode material influences the abundance and identity of the ions observed [19]. It is possible to change the electrode material in the PFT electrode emitter from carbon to another material and experiments with different electrode materials are planned.

\section{Acknowledgments}

ES-MS instrumentation was provided through a Cooperative Research and Development Agreement with MDS SCIEX (CRADA no. ORNL02-0662). VK and MJF acknowledge an ORNL appointment through the ORNL Postdoctoral Research Associates Program. The work carried out at ORNL was supported by the Division of Chemical Sciences, Geosciences, and Biosciences, Office of Basic Energy Sciences, United States Department of Energy under contract DE-AC05-00OR22725 with ORNL, managed and operated by UT-Battelle, LLC.

\section{References}

1. Applied Electrospray Mass Spectrometry; Pramanik, B. N.; Ganguly, A. K.; Gross, M. L., Eds.; Marcel Dekker: New York, NY, 2002.

2. Electrospray Ionization Mass Spectrometry; Cole, R. B., Ed.; Wiley: New York, NY, 1997.
3. Van Berkel, G. J. In Electrospray Ionization Mass Spectrometry; Cole, R. B., Ed.; Wiley: New York, NY, 1997, Chap II, pp 65-105.

4. De la Mora, J. F.; Van Berkel G. J.; Enke, C. G.; Cole, R. B.; Martinez-Sanchez, M.; Fenn, J. B. Electrochemical Processes in Electrospray Ionization Mass Spectrometry. J. Mass Spectrom. 2000, 35, 939-952.

5. Diehl, G; Karst, U. On-Line Electrochemistry-MS and Related Techniques. Anal. Bioanal. Chem. 2002, 373, 390-398.

6. Van Berkel G. J; McLuckey, S.A.; Glish, G. L. Electrochemical Origin of Radical Cations Observed in Electrospray Ionization Mass Spectra. Anal. Chem. 1992, 64, 1586-1593.

7. Van Berkel, G. J.; Zhou, F. Electrospray as a ControlledCurrent Electrolytic Cell: Electrochemical Ionization of Neutral Analytes for Detection by Electrospray Mass Spectrometry. Anal. Chem. 1995, 67, 2916-2923.

8. Van Berkel, G. J.; Quirke, J. M. E.; Tigani, R. A.; Dilley, A. S.; Covey, T. R. Derivatization for Electrospray Ionization Mass Spectropmetry. 3. Electrochemically Ionizable Derivatives. Anal. Chem. 1998, 70, 1544-1554

9. Quirke, J. M. E.; Hsu, Y-L.; Van Berkel, G. J. Ferrocene-Based Electroactive Derivatizing Reagents for the Rapid Selective Screening of Alcohols and Phenols in Natural Product Mixtures Using Electrospray-Tandem Mass Spectrometry. J. Nat. Prod. 2000, 63, 230-237.

10. Van Berkel, G. J.; Zhou, F. Observation of Gas-Phase Molecular Dications Formed from Neutral Organics in Solution via the Controlled-Current Electrolytic Process Inherent to Electrospray. J. Am. Soc. Mass Spectrom. 1996, 7, 157-162.

11. McCarley, T. D.; Lufaso, M. W.; Curtin, L. S.; McCarley, R. L. Multiply Charged Redox-Active Oligomers in the Gas-Phase: Electrolytic Electrospray Ionization Mass Spectrometry of Metallocenes. J. Phys. Chem. B 1998, 102, 10078-10086.

12. Rohner, T. C.; Rossier, J. S.; Girault, F. F. On-Line Electrochemical Tagging of Cysteines in Proteins During Nanospray. Electrochem. Commun. 2002, 4, 695-700.

13. Van Berkel, G. J.; Asano, K. G.; Granger, M. C. Controlling Analyte Electrochemistry in an Electrospray Ion Source with a Three-Electrode Emitter Cell. Anal. Chem. 2004, 76, 1493-1499.

14. Xu, X.; Lu, W.; Cole, R. B. On-Line Probe for Fast Electrochemistry/Electrospray Mass Spectrometry. Investigation of Polycyclic Aromatic Hydrocarbons. Anal. Chem. 1996, 68, 42444253.

15. Lu, W.; Xu, X.; Cole, R. B. On-Line Linear Sweep Voltammetry-Electrospray Mass Spectrometry. Anal. Chem. 1997, 69, 2478-2484.

16. Van Berkel, G. J. Insights into Analyte Electrolysis in an Electrospray Emitter from Chronopotentiometry Experiments and Mass Transport Calculations. J. Am. Soc. Mass Spectrom. 2000, 11, 951-960.

17. Van Berkel, G. J.; Zhou, F.; Aronson, J. T. Changes in Bulk Solution pH Caused by the Inherent Controlled-Current Electrolytic Process of an Electrospray Ion Source. Int J. Mass Spectrom Ion Processes 1997, 162, 55-67.

18. Van Berkel, G. J.; Kertesz, V. Redox Buffering in an Electrospray Ion Source Using a Copper Capillary Emitter. J. Mass Spectrom. 2001, 36, 1125-1132.

19. Van Berkel, G. J.; Asano, K. G.; Kertesz, V. Enhanced Study and Control of Analyte Oxidation in Electrospray Using Thin-Channel, Planar Electrode Emitter. Anal. Chem. 2002, 74, 5047-5056.

20. Kertesz, V.; Van Berkel, G. J. Minimizing Analyte Electrolysis in an Electrospray Emitter. J. Mass Spectrom. 2001, 36, 204-210.

21. Senko. M. IsoPro 3.0. This isotope calculation program can be downloaded from the internet web-address: http:// members.aol.com/msmssoft/ISOPRO30.HTM, 2004. 
22. Van Berkel, G. J. Electrolytic Corrosion of a Stainless-Steel Electrospray Emitter Monitored Using an Electrospray-Photodiode Array System. J. Anal. At. Spectrom. 1998, 13, 603-607.

23. Allen, M. J.; Powell, V. J. Anodic Polarography with a Rotating Platinum Microelectrode. J. Electrochem. Soc. 1958, 105, 541544.

24. Ebel, S.; Mück, W.; Placke, F. J. Analytical Oxidation of Reserpine. J. Pharm. Biomed. Anal. 1989, 7, 709-713.

25. Awang, D. V. C.; Dawson, B. A.; Girard, M.; Vincent, A. The Product of Reserpine Autooxidation. J. Org. Chem. 1990, 55, 4443-4448.

26. Kertesz, V.; Van Berkel, G. J. Investigation of Reserpine Oxidation Using On-Line Electrochemistry/Electrospray Mass Spectrometry. Poster presented at the 52nd ASMS Conference on Mass Spectrometry; Nashville, TN, May, 2004.

27. Blaedel, W. J.; Olson, C. L. Sharma, L. R. The Tubular Platinum Electrode. Anal. Chem. 1963, 35, 2100-2103.

28. Klatt, L. N.; Blaedel, W. J. Quasi Reversible and Irreversible Charge Transfer at the Tubular Electrode. Anal. Chem. 1967, 39, 1065-1072.

29. Symons, P. G. Modeling of Electroanalytical Systems: Microtube Flowing Coulometry. M.S. Thesis, Trent University, Peterborough, Ontario, 1995.
30. Chen, L.; Colyer, C. L.; Kamau, M. G.; Myland, J. C.; Oldham, K. B.; Symons, P. G. Microtube Flowing Coulometry. Can. J. Chem. 1994, 72, 836-849.

31. Van Berkel, G. J.; Giles, G. E.; Bullock, J. S., IV; Gray, L. J. Novel Computational Simulation of Redox Reactions Within a Metal Electrospray Emitter. Anal. Chem. 1999, 73, 5288-5296.

32. Bruins, A. P. In Electrospray Ionization Mass Spectrometry; Cole, R. B., Ed.; Wiley: New York, 1997, Chap III, pp 107-136.

33. Konermann, L.; Silva, E. A.; Sogbein, O. F. Electrochemically Induced $\mathrm{pH}$ Changes Resulting in Protein Unfolding in the Ion Source of an Electrospray Mass Spectrometer. Anal. Chem. 2001, 73, 4836-4844.

34. Holler, F. J.; Enke, C. G. Conductivity and Conductometry. In Laboratory Techniques in Electroanalytical Chemistry; Kissinger, P. T.; Heineman , W. R., Eds.; Marcell Dekker: New York, 1996, Chap VIII, pp 237-265.

35. Whitehouse, C. M.; Dreyer, R. N.; Yamashita, M.; Fenn, J. B. Electrospray Interface for Liquid Chromatographs and Mass Spectrometers. Anal. Chem. 1985, 57, 675-679.

36. Steckham, E. Electrosynthesis. In Laboratory Techniques in Electroanalytical Chemistry; Kissinger, P. T.; Heineman, W. R., Eds; Marcel Dekker: New York, NY, 1996, Chap XXII, pp 676-681. 